www.jmscr.igmpublication.org

Impact Factor (SJIF): 6.379

Index Copernicus Value: 71.58

ISSN (e)-2347-176x ISSN (p) 2455-0450

crossref DOI: _https://dx.doi.org/10.18535/jmscr/v6i3.188

Journal Of Medical Science And Clinical Research

\title{
Morphometric Evaluation of the Frontal Sinus and Nasal Septum as an Aid in Personal and Gender Identification- A Retrospective Digital Radiographic Study
}

\author{
Authors \\ Dr Varsha Kanjani ${ }^{1}$, Dr Rajeshwari G. Annigeri², Dr Manjunath M. Revanappa ${ }^{3}$, \\ Dr Tejaswini N G ${ }^{4}$, Dr Nimesh Jain ${ }^{5}$, Dr Neha Sharma ${ }^{6}$ \\ ${ }^{1,5,6}$ Post Graduate, ${ }^{2}$ Professor and HOD, ${ }^{3}$ Associate Professor, ${ }^{4}$ Reader \\ Department of Oral Medicine and Radiology, College of Dental Sciences, Davangere \\ Corresponding Author \\ Dr Varsha Kanjani
}

Department of Oral Medicine and Radiology, College of Dental Sciences, Davangere, India - 577004

Phone number - 91 8147671525, 91 7019961896, Email: varshakanjani0@ gmail.com

\begin{abstract}
Introduction: Human skull radiography is a useful tool in identification in natural disaster, in any accidents such as fire accident and road traffic accident where body remains become degraded or severely destroyed. The singularity in the frontal sinus and nasal septum morphology plays salient role in personal identification and gender determination.

Aim: Present study was performed to evaluate the height and width of frontal sinus along with various patterns of frontal sinus (FS) and nasal septum (NS) observed on posterior-anterior (PA) cephalogram for personal identification and gender determination.

Materials and Methods: A total of 140 PA Cephlograms, 70 males and 70 females, above 18 years were selected. The mean height and width of the FS in males and females were determined. FS and NS patterns were evaluated and both patterns were also compared.

Results: In males, the mean height and width of FS were greater than in females. For each individual, patterns were analyzed together. Out of 140 individuals, 113 unique combinations of FS and NS patterns were seen.

Conclusion: The morphologic evaluation of frontal sinus along with frontal sinus and nasal septum patterns can serve as an adjunct to other methods of personal identification and gender determination.

Keywords: Personal identification, Frontal Sinus, Nasal Septum, PA cephalogram.
\end{abstract}

\section{Introduction}

Personal identification is defined as establishing the identity of an individual. When the body is decayed, decomposed, putrefied or burnt to deliberately reveal humans identity or in cases of mass calamities (such as earth quakes, tsunamis, landslides, bomb blasts), the need for personal identification and gender determination plays an important role. ${ }^{1}$ 
In younger age and teenagers, growth and development of frontal sinus (FS) and nasal septum (NS) may manacle the manifestation of sexually dimorphic features and hence approaches for gender determination are practiced on the fully developed skeleton. The dead and deceased human remains identification forms cardinal element in medico-legal cases ${ }^{2}$.

Investigations, in which ante mortem and postmortem radiographic records are compared, are commonly used for personnel identification both in human remains and in living individuals. For forensic identification of unknown decomposed or deceased individuals, the singularity of anatomical structures and their variations plays a significant role $^{3}$.

FS, NS, sellaturcica, vascular groove patterns etc., are unique anatomical structures for human skull identification in forensics ${ }^{4}$. Like finger prints, even the FS is very unique in every individual, even in monozygotic twins. The FS development completes at the age of 20 years ${ }^{5}$. The NS pattern is also useful and unique tool. The use of different FS and NS patterns together helps in a more accurate identification, rather than using one anatomical structure alone. ${ }^{6}$

Therefore, the present study was commenced to assess FS dimensions andto analyze the combination of FS and NS patterns as observed on posterior anterior cephalogram, for personal identification.

\section{Materials and Methods}

PA cephalograms of 186 individuals visiting the Department of Oral Medicine and Radiology, College of Dental Sciences, Davangere city, between the age group of 20 - 45 years were enrolled in the study. Individuals with history of trauma or surgery of the skull or nose, any nasal cavity or FS pathology, endocrinal or metabolic disorder affecting the growth, and development of FS or nose and syndromic patients were excluded from the study. Out of 186, 19 with the history of trauma were excluded from the study and 27 on radiographic examination were having unilateral / bilateral aplasia of FS, were considered only for FS patterns. The selected PA cephalograms were examined for FS measurements alongwith FS and NS patterns. Institutional ethical clearance was taken before commencing the study.

Measurements were done using ROMEXIS software. The width of the FS was calculatedas the maximum lateral limits from central septum and height was measured from frontonasal suture to the superior most point of the FS.(Figure 1). ${ }^{7}$

Based on the symmetry, FS was classified as symmetrical or asymmetrical (right orleft dominant), along with unilateral or bilateral aplasia (Figure 2). The right and left side difference in dimensions of FS was divided by their greatest dimension and was multiplied by 100. If the obtained percentage is less than 20, FS was considered as symmetrical and if it is more than 20, FS was classified as asymmetrical (Figure 3). The numbers of lobulations on each side were also analyzed. The NS was classified as straight, deviation to right or left, sigmoid type and reverse sigmoid type (Figure 4). The combined patterns were noted for each radiograph. ${ }^{7}$

The results were analyzed using Statistical Package of Social Sciences (SPSS) software version 21. The dimensions of FS between males and females were compared using paired t-test. The significance of occurrence of a particular entity was expressed as p-value less than 0.05. Pearson's correlation coefficient was used to determine the correlation between different patterns of FS and NS.

\section{Results}

The mean age of males and females enrolled in the study was $27.37 \pm 6.78$ years and $24.38 \pm 5.35$ years respectively.

Out of 140 individuals, the mean height with SD of FS in males was $21.28 \pm 2.64 \mathrm{~mm}$ and in females, was $15.64 \pm 2.05 \mathrm{~mm}$. The mean width with SD of frontal sinus in males was $53.15 \pm$ $7.15 \mathrm{~mm}$ and in females it was $33.22 \pm 8.87 \mathrm{~mm}$. On intergroup comparison, the difference in 


\section{JMSCR Vol||06||Issue||03||Page 1154-1161||March}

dimensions of males and females were statistically significant in both the genders with p-value of 0.000 ( $\mathrm{p}<0.001)$. (Table 1and Graph 1)

The present study revealed that out of 140, FS symmetry was observed in 110 individuals (78.57\%). FS asymmetry was observed in 30 individuals (32\% - 9 right and 21 left). Out of 46 individuals, 27 were having unilateral or bilateral aplasia (Table 2 and Graph 2). The FS bilateral aplasia was seen in 16 individuals and unilateral aplasia was observed in 21 individuals (18 right unilateral and 3 left unilateral). (Table 2 and Graph 3)
Straight NS was seen in 100 individuals (66.66\%). Left and right deviation in NS was seen equally in males and female (12\% and $10.66 \%$ respectively). Sigmoid was seen in 4 individual $(2.6 \%)$ and reverse sigmoid in 2 individual $(1.33 \%$ ) (Table 3 and Graph 4)

In the present study, out of 140 individuals, 113 unique combinations of FS and NS patterns were found. However, there were 27 individuals whose patterns matched one of the patterns of the 113 individuals.

Figure 1 Dimensions for measuring height and width of FS

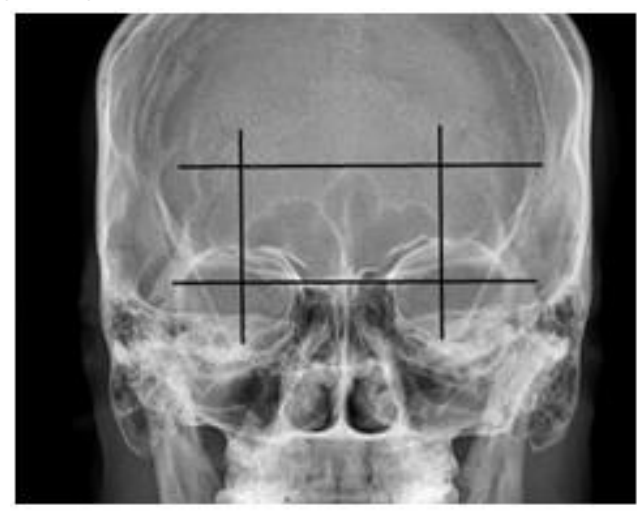

Figure 2 -Different patterns of Frontal Sinus - (A) Symmetrical, (B) Left dominated asymmetry, (C) Right dominated asymmetry, (D) Unilateral aplasia and (E) bilateral aplasia.

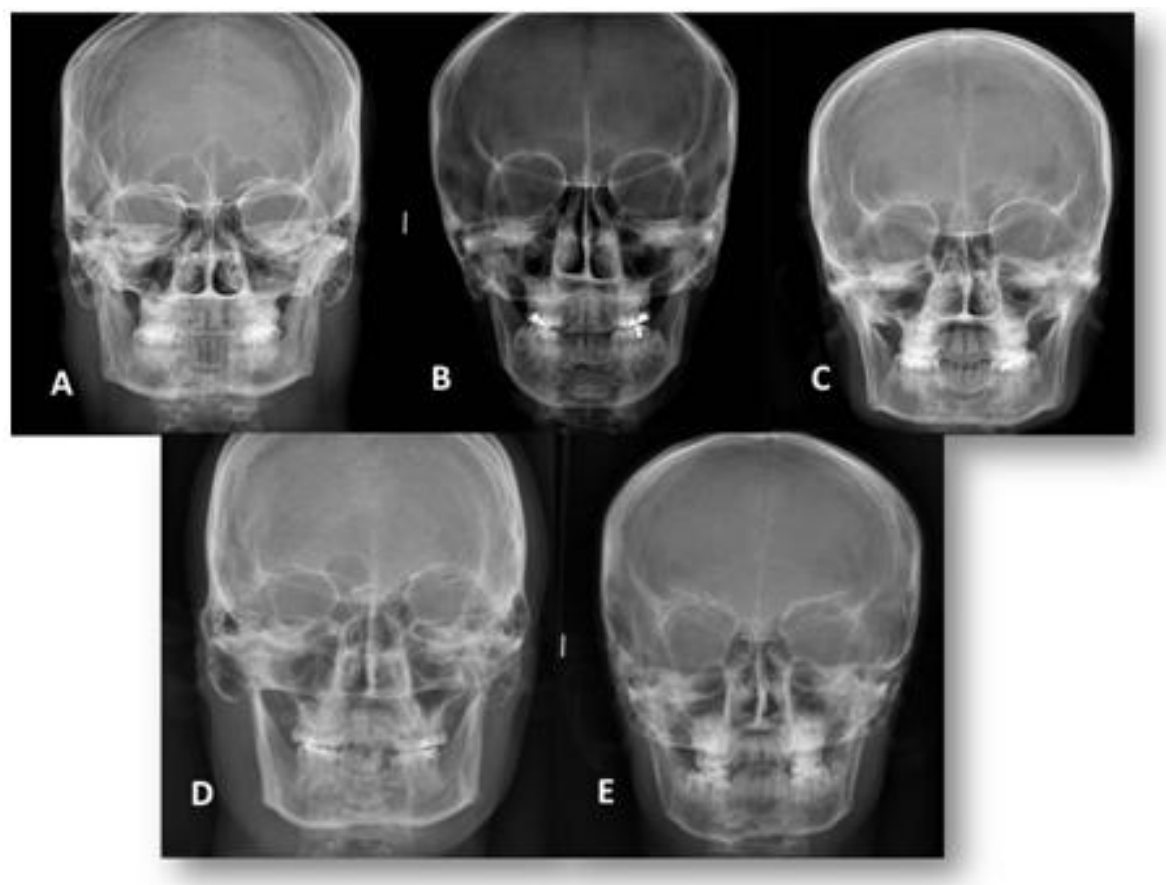




\section{JMSCR Vol||06||Issue||03||Page 1154-1161||March}

Figure 3 Method for determining symmetrical or asymmetrical Frontal Sinus pattern

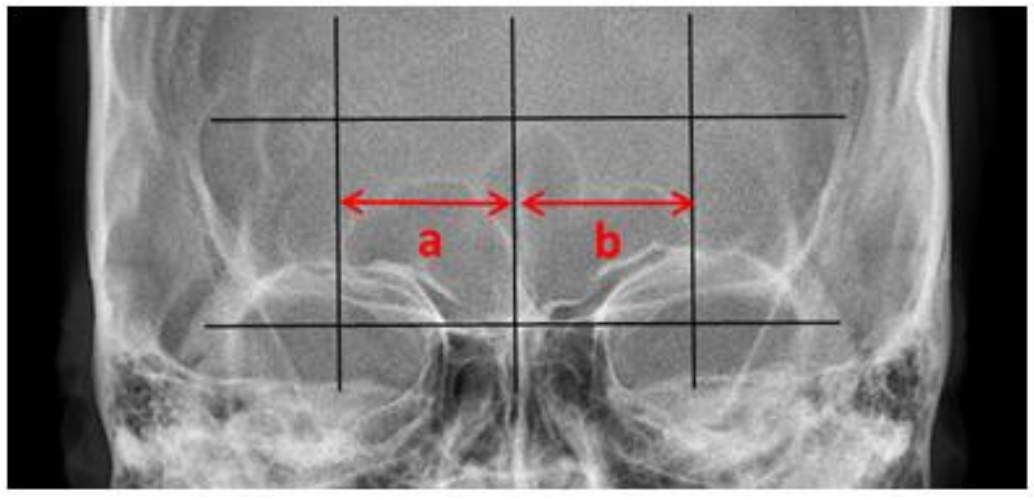

Figure 4 Different patterns of nasal septum - (A) Straight, (B) Right deviated, (C) Left deviated, (D) Sigmoid and (E) Reverse sigmoid.

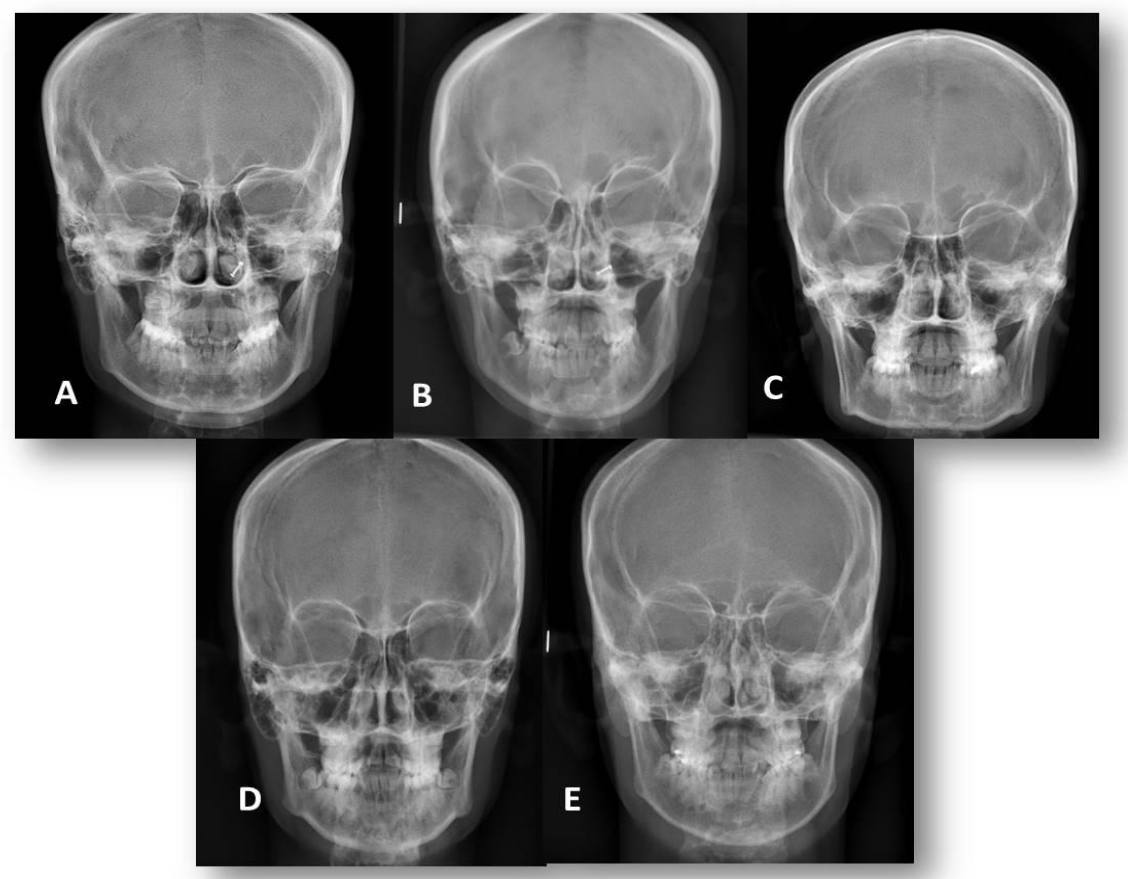

Table 1 Dimensions of Frontal Sinus among males and females

\begin{tabular}{|l|c|c|c|}
\hline & MALES & FEMALES & P VALVE \\
\hline HEIGHT & $21.28 \pm 2.64$ & $15.64 \pm 2.05$ & $\mathbf{0 . 0 0 0} *$ \\
\hline WIDTH & $53.15 \pm 7.15$ & $33.22 \pm 8.87$ & $\mathbf{0 . 0 0 0} *$ \\
\hline
\end{tabular}

Table 2 Distribution of Frontal Sinus patterns

\begin{tabular}{|l|c|c|c|}
\hline CLASSIFICATION & NUMBER OF INDIVIDUALS & TOTAL \\
\hline & MALES & FEMALES & \\
\hline Symmetry & 52 & 58 & 110 \\
\hline Left Dominant Asymmetry & 12 & 09 & 21 \\
\hline Right Dominant Asymmetry & 06 & 03 & 09 \\
\hline Left Unilateral Aplasia & 03 & 0 & 03 \\
\hline Right Unilateral Aplasia & 09 & 09 & 18 \\
\hline Bilateral aplasia & 08 & 09 & 17 \\
\hline
\end{tabular}




\section{JMSCR Vol||06||Issue||03||Page 1154-1161||March}

Table 3 Distribution of Nasal Septum patterns

\begin{tabular}{|l|c|c|c|}
\hline CLASSIFICATION & \multicolumn{2}{|c|}{ NUMBER OF INDIVIDUALS } & TOTAL \\
\hline & MALES & FEMALES & \\
\hline Straight & 52 & 48 & 100 \\
\hline Left deviated & 09 & 09 & 18 \\
\hline Right deviated & 08 & 08 & 16 \\
\hline Sigmoid & 01 & 03 & 04 \\
\hline Reverse Sigmoid & 00 & 02 & 02 \\
\hline
\end{tabular}

Graph 1 Dimensions of Frontal Sinus among males and females

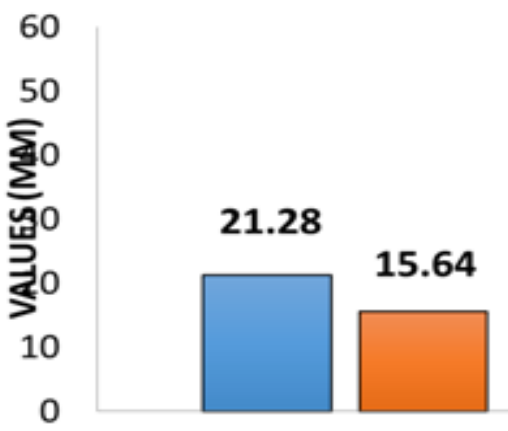

HEIGHT
53.15

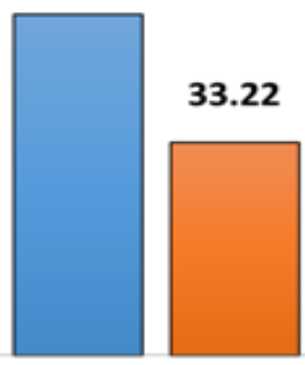

WIDTH

MALES $\square$ FEMALES

Graph 2 Distribution of Frontal Sinus patterns (Symmetry and Asymmetry)

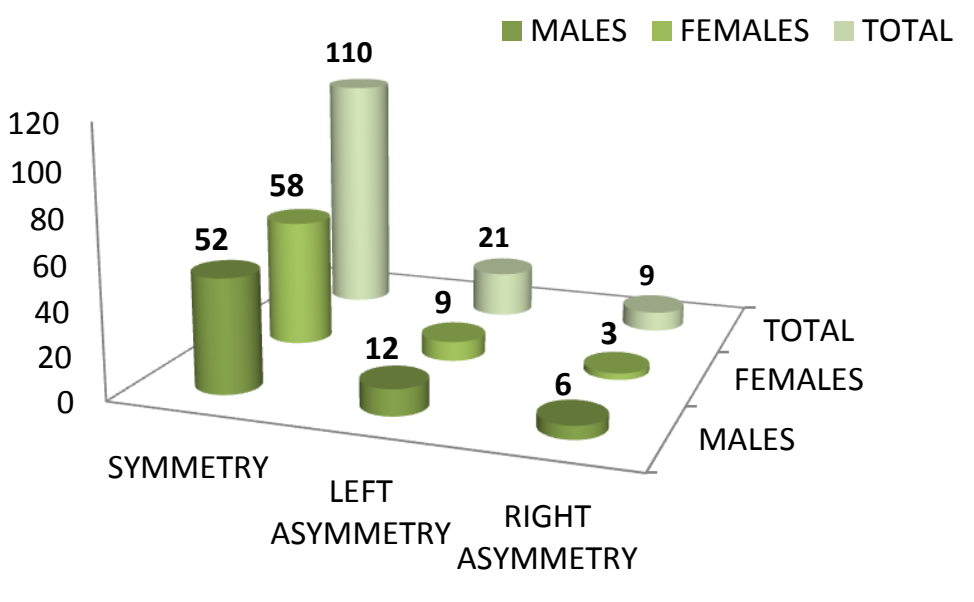

Graph 3 Distribution of Frontal Sinus patterns (Unilateral and Bilateral aplasia)

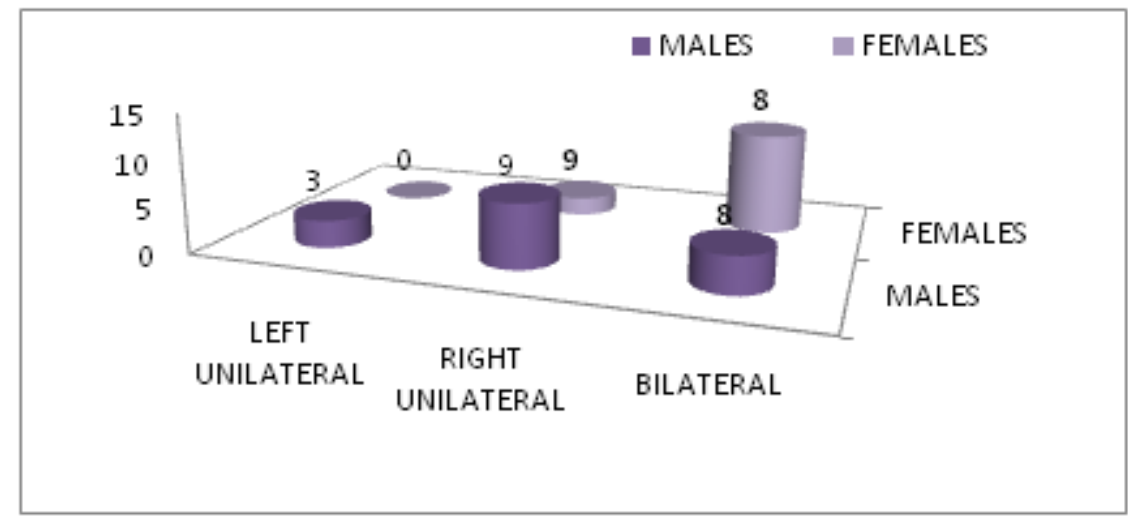


Graph 4 Distribution of Nasal Septum patterns

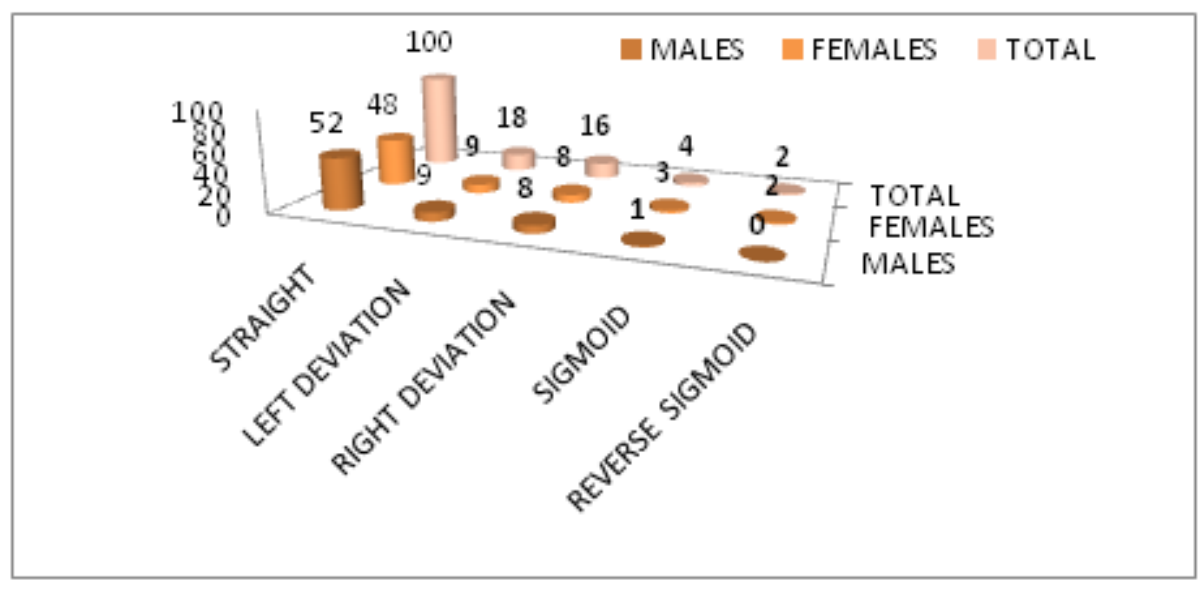

\section{Discussion}

In 1875, Zukerkandl ${ }^{8}$ observed the uniqueness of FS due to its asymmetrical morphology. Frontal sinus and nasal septum patterns together has proven to be a very useful tool for identification purposes in forensics ${ }^{9}$ The present study was undertaken with the intention to measure FS dimensions and to analyze FS and NS patterns using single radiograph (PA cephalogram) with minimal distortion and to use the same in personal identification.

In the present study as far as the age was concerned the patients were selected in the age range from 18 to 45 years with a mean age of 26.49 years, because FS develops upto the age of 18-20 years. This was in compliance with the studies conducted by Libersa and Faber (1957), Krogman (1962), and Porbonikova (1974). Also the growth of the nose increases until the age of 18 , as suggested by Antoszewski et al. ${ }^{10}$ Quatrehommeet $\mathrm{al}^{11}$ suggested that bone resorption is the common finding in the advancing age, therefore, individuals up to the age of 45 years were enrolled in the study. Frontal sinus patterns when combined with nasal septum patterns may also be useful for identification and gender determination of an individual.

In our study, males and females were equal in number i.e 70 males and 70 females (50\% each), which is similar to the studies conducted by Verma K et al (2017) ${ }^{4}$, Tiwari P et al (2016) ${ }^{12}$, Hamed SS et al (2014) ${ }^{13}$, Mathur H et al (2013) ${ }^{14}$,
Patil N et al $(2012)^{3}$, Maria PD et al $(2010)^{10}$ and Camargo RJ et al (2007) ${ }^{15}$. In contrast to these, 150 males and 130 females were taken in study published by Nagarj T (2017) ${ }^{16}$ and 74 males and 75 females were enrolled in study published by Verma P et al $(2015)^{7}$. In Cakur B et al $(2011)^{17}$ study, 190 males and 220 females were included. Similarly, 116 males and 29 females were used in a study conducted by Rubira-Bullen IRF et al (2010). ${ }^{18}$

The mean height of FS in males and females were $21.28 \pm 2.64 \mathrm{~mm}$ and $15.64 \pm 2.05 \mathrm{~mm}$ respectively, revealed that mean height in males is significantly greater than mean height in females. The present study also compared the mean width of FS in males and females stating that males had mean width of $53.15 \pm 7.15 \mathrm{~mm}$, which was highly significant greater than mean width of $33.22 \pm 8.87 \mathrm{~mm}$ in females. The above data suggested that mean height and width of FS is greater in males as compared to females and can be used as a criterion for gender determination in forensics which was in accordance with the studies published by Yoshino M (1987) ${ }^{19}$ and Verma K et al (2017) ${ }^{4}$.

In the present study, FS symmetry and asymmetry were found to be in $78.57 \%$ and $21.42 \%$, respectively, which were in accordance with David M P et al (58\% and 32\%) (2010) ${ }^{10}$ Nagaraj $\mathrm{T}$ et al (78\% and 11.4\%) (2017) ${ }^{16}$ and Verma K et al $(77.5 \%$ and $22.5 \%)(2017)^{4}$. The present study differed from that done by Taniguchi $\mathrm{M}$ et al 
$(2003)^{6}$ stating that $43.1 \%$ cases had symmetry of FS and $56.6 \%$ had asymmetrical patterns.

In the present study, unilateral absence of FS was seen in $18(9.6 \%)$ of 186 individuals. These findings are in accordance with the studies done by Verma $\mathrm{K}$ et al $(2017)^{4}$ and Tiwari $\mathrm{P}$ et al $(2016)^{12}$ with $8.7 \%$ and $13.75 \%$ cases respectively and in contrast to the studies done by David M P et al $(2010)^{10}$, Gopal et al $(2017)^{20}$ and Nagaraj T $(2017)^{16}$ who observed $6 \%, 2.5 \%$ and $5.7 \%$ respectively. Bilateral aplasia was found to be 17 $(9.1 \%)$ in our study which was in total contrast with the studies done by Gopal et al. $(2017)^{20}$ who did not observe in any case, David $\mathrm{M} P$ et al $(2010)^{10}$ with $4 \%$, Tiwari P et al (2016) ${ }^{12}$ with $5 \%$ and Nagaraj $\mathrm{T}$ et al $(2017)^{16}$ with $4.6 \%$ cases and in favor of Taniguchi et al (2003) ${ }^{6}$ in which $10.8 \%$ cases were found.

Various NS patterns were observed in the present study. The straight pattern was observed in 100 $(71.42 \%)$, left deviated in $18(12.85 \%)$, right deviated in $16(11.42 \%)$ which is in contrast with Taniguchi et al (2003), David M P et al (2010), Verma $\mathrm{K}$ et al (2017) and Nagaraj $\mathrm{T}$ et al (2017). ${ }^{6,10,4,16}$ Sigmoid and reverse sigmoid patterns were assessed in $4(2.85 \%)$ and 2 $(1.42 \%)$ of the total individuals in our study, which is in accordance with Taniguchi et al (2003), David M P et al (2010), Verma K et al (2017) $6,10,4$

On assessing both FS and NS patterns, 113 unique combinations were obtained and 27 individuals, whose patterns matched one of the patterns of the 113 individuals. The NS and FS pattern correlation was found to be statistically significant. The results were in favor of the study published by Taniguchi $\mathrm{M}$ et al ${ }^{6}$, stating that FS and NS patterns combined leads to a more accurate identification rather than using single pattern

Digital PA cephalograms were used in the present study as it demonstrates adequate FS morphology and NS patterns with minimal distortion and maximum detail on a single radiograph. In similar studies conducted by Reddy S et al $(2014)^{21}$,
Mohan V et al (2015) ${ }^{22}$, Nagaraj T et al $(2017)^{16}$ and Verma $\mathrm{K}$ et al $(2017)^{4}$ used digital PA cephalograms for analysis. However, Caldwell view was used in studies conducted by Camargo RJ et al (2007) ${ }^{15}$, Rubira-Bullen IRF et al (2010) ${ }^{18}$ and Patil $\mathrm{N}$ et al (2012) ${ }^{3}$.

Due to the varying FS size during development, the individuals above the age of 18 were taken in the present study. The variations in size of FS may be related to environmental, hormonal and genetic factors. Secondly, a more precise measuring tool should be used with less margin of error. Therefore, age-wise distribution and larger sample size with more précised advanced tool is recommended.

\section{Conclusion}

The radiographic evaluation of frontal sinus dimensions, frontal sinus patterns, nasal septum deviations and the combination $(\mathrm{FP}+\mathrm{NS})$ patterns is one of the aids for personal identification and gender determination in forensic investigations by using a single radiograph with minimal distortion and maximal details.

\section{References-}

1. Modi JP (2011) A Textbook of Medical Jurisprudence and Toxicology, 24th Edn, LexisNexis Butterworths, Nodia.

2. Kanchan T, Krishan K (2013) Personal Identification in Forensic Examinations. Anthropol 2: 114.

3. Patil N, Karjodkar FR, Sontakke S, Sansare $\mathrm{K}$, Salvi R. Uniqueness of radiographic patterns of the frontal sinus for personal identification. Imaging science in dentistry. 2012 Dec 1;42(4):213-7.

4. Verma K, Nahar P, Singh MP, Mathur H, Bhuvaneshwari S. Use of Frontal Sinus and Nasal Septum Pattern as an Aid in Personal Identification and Determination of Gender: A Radiographic Study. Journal of clinical and diagnostic research: JCDR. 2017 Jan;11(1):ZC71. 
5. Tang JP, Hu DY, Jiang FH, Yu XJ. Assessing forensic applications of the frontal sinus in a Chinese Han population. Forensic SciInt 2009; 183 : 104.e1-3.

6. Taniguchi M, Sakoda S, Kano T, Zhu BL, Kamikodai Y, Fujita MQ, et al. Possible use of nasal septum and frontal sinus patterns to radiographic identification of unknown human remains. Osaka City Med J. 2003;49(1):31-38.

7. Verma P, Verma KG, Khosa R, Kumar S, Basavaraju S, Patwardhan N. Combined use of frontal sinus and nasal septum patterns as an aid in forensics: A digital radiographic study. North American journal of medical sciences. $2015 \mathrm{Feb} ; 7(2): 47$.

8. Zukerkandl E, Lichtwitz L, Garnault P. Anatomy of the frontal sinus. In normal and pathological anatomy of the nasal cavity. Vol 1, 3rd ed. Paris: G Masson; 1895. p. 349-61.

9. Campobasso CP, Dell'Erba AS, Belviso M, Di Vella G. Craniofacial identification by comparison of antemortem and postmortem radiographs: two case reports dealing with burnt bodies. The American journal of forensic medicine and pathology. 2007 Jun 1;28(2):182-6.

10. David MP, Saxena R. Use of frontal sinus and nasal septum patterns as an aid in personal identification: A digital radiographic pilot study. Journal of forensic dental sciences. $2010 \mathrm{Jul} ; 2(2): 77$.

11. Quatrehomme G, Fronty P, Sapanet M, Grévin G, Bailet P, Ollier A. Identification by frontal sinus pattern in forensic anthropology.ForensicSciInt 1996;83:147-53.

12. Tiwari P, Bhovi TV, Jaju PP, Gupta M, Shrivastava K. Frontal Sinus-A Useful Personal Identification Tool. Journal of Oral Medicine, Oral Surgery, Oral Pathology and Oral Radiology. 2016;2(1):11-22.

13. Hamed SS, Badrawy AM and Fattah SA Gender identification from frontal sinus using multi-detector computed tomography. J Forensic RadiolImg. 2014; 2(3): 117-120.

14. Mathur H, Mathur A, Ahmed J, Khorate M and Tripathi $\mathrm{P}$. Conventional frontal sinus imaging in identification of sex: Original study in population of Udaipur city, India. $\mathbf{J}$ Med SciClin Res. 2013; 1(1): 33-37.

15. Camargo RJ, Daruge E, Prado FB, Caria PHF, Alves MC, Silva RFet al. The frontal sinus morphology in radiographs of Brazilian subjects: its forensic importance. Braz J Morpholo Sci. 2007; 24(4): 239-243.

16. Nagaraj T, Nigam H, Santosh HN, Sumana CK, Gogula S, Sahu P. Personal identification using frontal sinus and nasal septum patterns in forensic medicine: A retrospective digital radiographic study.

17. Cakur B, Sumbullu MA and Durna NB. Aplasia and agenesis of the frontal sinus in Turkish individuals: A retrospective study using dental volumetric tomography. Int $\mathrm{J}$ Med Sci. 2011; 8(3): 278-282.

18. Rubira-Bullen IRF, Rubira CMF, Sarmento VA and Azevedo RA. Frontal sinus on facial plain radiographs. J Morphol Sci. 2010; 27(2): 77-81.

19. Yoshino M, Miyasaka S, Sato H, Seta S. Classification system of frontal sinus pattern by radiography. Its application to identification of unknown skeletal remains. Forensic Sci Int. 1987;34(4):289-99.

20. Gopal KS, Vijayan BP. Significance of frontal sinus and nasal septum patterns in personal identification in forensics: A retrospective CBCT study. Int J Oral Health Med Res 2016;2:57-62.

21. Reddy S, Alapati S and Kotha P. Unleash the unknown- Frontal sinus and nasal septal patterns in personal identification. 2014; 2(6): 141-145.

22. Mohan V, Kumar JS, Kumar SC and Neha. Morphometric evaluation of frontal sinus in relation to gender- A forensic study. University J Dent Sci. 2015; 1(2): 7-11. 